\title{
Evaluation of the Abbott RealTime quantitative CMV and EBV assays using the maxCycle protocol in a laboratory automation context
}

\author{
Sébastien Bontems ${ }^{\mathrm{a}, *}$, Raphaël Boreux ${ }^{\mathrm{a}}$, Valérie Capraro ${ }^{\mathrm{b}}$, Pascale Huynen ${ }^{\mathrm{a}}$, Julie Descy ${ }^{\mathrm{a}}$, \\ Pierrette Melin ${ }^{\mathrm{a}}$, Marie-Pierre Hayette ${ }^{\mathrm{a}}$, Cécile Meex ${ }^{\mathrm{a}}$ \\ ${ }^{a}$ Laboratory of Clinical Microbiology, Unilab-Lg, CHU of Liege, 1 avenue de l'hopital, 4000 Liege, Belgium \\ ${ }^{\mathrm{b}}$ Molecular Biology Platform, Unilab-Lg, CHU of Liege, 1 avenue de l'hopital, 4000 Liege, Belgium
}

A R T I C L E I N F O

\section{Keywords:}

CMV

EBV

Automation

Abbott maxCycle

\begin{abstract}
A B S T R A C T
Real-time PCR are often used for the diagnosis and monitoring of Cytomegalovirus (CMV) and Epstein-Barr virus (EBV) infections in susceptible populations. In this context, we evaluated the analytical performances of the Abbott RealTime CMV/EBV maxCycle protocol automated on the $m 2000$ platform (Abbott). It was compared to our routinely-used procedure consisting of a NucleoMag ${ }^{\circledast}$ DNA extraction automated on a STARlet platform followed by manually processed CMV and EBV quantitative real-time PCR (Diagenode). In this study, we showed that both EBV assays exhibited a similar sensitivity but with a better precision for the EBV Abbott RealTime assay. For the CMV performances, the Abbott assay was more sensitive and more precise than our routine method. The use of WHO International Standards also indicated a slight underestimation of the viral loads $\left(-0.25 \log _{10} \mathrm{IU} / \mathrm{mL}\right.$ and $-0.21 \log _{10} \mathrm{IU} / \mathrm{mL}$ for CMV and EBV assays respectively) while these were rather overestimated with the Starlet/Diagenode method $\left(0.48 \log _{10} \mathrm{IU} / \mathrm{mL}\right.$ and $0.19 \log _{10} \mathrm{IU} / \mathrm{mL}$ for CMV and EBV assays respectively). These trends were confirmed using relevant whole-blood clinical samples and external quality controls. The workflows were also compared and we highlighted a significant technician hands-on time reduction $(-63 \%)$ using the Abbott CMV/EBV maxCycle automated protocol.
\end{abstract}

\section{Introduction}

Automation plays an increasingly important role in the routine activity of clinical laboratories, with the consolidation of specific activities such as biochemical analyses, hematology or serological diagnosis through core-lab facilities (Hawker, 2007), with the development of integrated solutions for bacteriological culture and antimicrobial susceptibility testing (Croxatto et al., 2016; Dauwalder et al., 2016), but also in the molecular diagnostic field. This predictable change (Felder et al., 1988) became a reality due to economic constraints, workload pressure and the need for laboratories to deliver results in short turnaround-times and has been made possible with the evolution of technology not only in large structures but also in smallest clinical laboratories.

In our university hospital (CHU), where many hematological and solid organ transplantations are performed, two of the most important analytical parameters conducted for the management of these patients are the CMV and EBV viral load determinations. Cytomegalovirus
(CMV) and Epstein-Barr virus (EBV) are members of the Herpesviridae family and are able to establish a life-long persistent and latent infection within their human host after primary infection. They are both able to reactivate frequently throughout the lifespan and to disseminate within the infected body. In immunocompromised patients, CMV reactivation can lead to serious complications like allograft rejection (Dioverti and Razonable, 2016) while EBV infection is associate to malignant B cell lymphoproliferations (Martinez and Krams, 2017). According to international guidelines, the use of quantitative EBV and CMV PCR in blood is indicated in all hematopoietic stem cell transplant (HSCT) or solid organ transplant (SOT) recipients to allow early initiation of antiviral therapies and also for their monitoring (Gulley and Tang, 2010; Heemann et al., 2011; Kotton et al., 2013; Torre-Cisneros et al., 2016).

The increasing number of samples to be tested requires more and more automated solutions in clinical laboratories. In this context, the Abbot CMV and EBV RealTime assays automated on the Abbott $m 2000$ platform were assessed and their analytical performances were

\footnotetext{
* Corresponding author.

E-mail addresses: sbontems@chuliege.be (S. Bontems), Raphael.Boreux@chuliege.be (R. Boreux), Valerie.Capraro@chuliege.be (V. Capraro), p.huynen@chuliege.be (P. Huynen), julie.descy@chuliege.be (J. Descy), Pierrette.Melin@chuliege.be (P. Melin), mphayette@chuliege.be (M.-P. Hayette), c.meex@chuliege.be (C. Meex).
} 
compared to our currently used two-steps procedure consisting of a NucleoMag ${ }^{\circledast}$ (Macherey-Nagel) whole-blood DNA extraction automated on a STARlet platform (Hamilton) followed by a manually processed quantitative real-time PCR using CMV and EBV commercial assays (Diagenode). To achieve this, CMV and EBV WHO International Standards were used as well as whole blood (WB) clinical samples and several panels of external quality controls (QCMD). The Abbott Realtime CMV/EBV maxCycle protocol allows the EBV and CMV viral load determination in a single run. We have thus compared the workflow and the turnaround time (TAT) for WB samples using this CMV/ EBV maxCycle protocol to the routinely used Starlet/Diagenode method in order to estimate the technical time saved when this full automated Abbott protocol is used.

\section{Materials and methods}

\subsection{Samples collection and standards}

A total of 112 whole blood samples from 52 patients ( 34 males and 18 females, median age: 47.9 years, range: $5.5-73$ years) hospitalized in our institution were collected in EDTA tubes and included in this study. Samples were stored at $4^{\circ} \mathrm{c}$ before being processed. PCR were performed on both platforms within a median delay of 1 day (interval: 1 to 8.5 days) and 3 days (interval: 1 to 6 days) for CMV and EBV analysis respectively. WHO International Standards (IS) from the National Institute for Biological Standards and Controls (NIBSC, Hertfordshire, United-Kingdom) were used in this study: the 1st WHO International Standard for HCMV for Nucleic Acid Amplification Techniques (NIBSC code: 09/162) comprised a whole virus preparation of the HCMV Merlin strain while the 1st WHO International Standard for EBV for Nucleic Acid Amplification Techniques (NIBSC code: 09/260) comprises a whole virus preparation of the EBV B95-8 strain (type 1).

Several panels of external controls from the Quality Controls for Molecular Diagnostics organization (QCMD, Glasgow, UK) were also used in this study (CMVWB16C1, EBVWB15C2 and EBVWB16C1). These controls were processed as clinical samples and their viral loads were assessed on both platforms in parallel.

\subsection{Whole blood extraction and Real-Time PCR using the Starlet/ Diagenode system}

Whole-blood DNA extraction was performed using the NucleoMag ${ }^{\oplus}$ Blood $200 \mu \mathrm{L}$ kit (Macherey-Nagel GmbH \&Co.KU, Düren, Germany) automated on a STARlet platform (Hamilton) following manufacturer's instructions Briefly, $200 \mu \mathrm{L}$ of whole blood were lysated in a buffer containing proteinase $\mathrm{K}$ and paramagnetic beads were used to remove contaminants and salt while elution was performed using a low-salt buffer. In its home-made configuration, the STARlet platform allows the automated DNA extraction of 80 samples in a single run.

EBV and CMV DNA quantification were performed using the Diagenode Real-Time quantitative PCR kits (Dia-EBVQ-050 and DiaCMVQ-050 respectively, Diagenode, Seraing, Belgium) following manufacturer's recommendation. Distribution of the Diagenode Internal Control (DNA virus culture) for extraction in each sample was performed using the STARlet platform before extraction. Mastermix additions $(20 \mu \mathrm{L})$ to the eluated DNA $(5 \mu \mathrm{l})$ were done manually and the RTPCR runs were performed on an ABI7500 thermocycler (Thermo Fisher Scientific, Waltham, USA). When the EBV and CMV quantifications were requested for the same sample, a single extraction was performed on the STARlet platform for this sample and the EBV and CMV PCR were run separately. Quantifications were achieved for both tests by comparing Ct values obtained for each samples to a specific 5 points calibration curve established for each run. Results are expressed in copies/mL for EBV and CMV or in International Units (IU)/mL for CMV only. According to the manufacturer, the limit of detection (LOD) for the Diagenode CMV test was $820 \mathrm{IU} / \mathrm{mL}\left(2.91 \log _{10} \mathrm{IU} / \mathrm{mL}\right)$ and 822
copies/mL for the Diagenode EBV test when samples were extracted using an EasyMag (Biomerieux) and PCR performed on a LC480 (Roche) or a CFX96 (Biorad) thermocycler respectively. Since the manufacturer provided no information on the Limit of Quantification (LOQ) for these tests, we extrapolated them as being equal to the LOD.

\subsection{EBV and CMV quantification using the Abbott m2000 platform}

The Abbott $m 2000$ system used was a 2-parts platform composed of extraction (m2000sp) and detection automates (m2000rt). The $m 2000$ sp allowed the simultaneous extraction of 48 samples for EBV or CMV quantification as well as the automated distribution of eluated DNA and mastermix in a RT-PCR plate. DNA extractions were per-

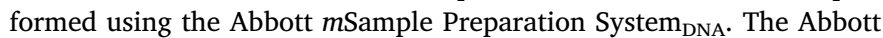
RealTime CMV/EBV maxCycle protocol was used for this study: it allowed the management of CMV and EBV samples in a single run but required a specific extraction for each test, in two different tubes, when both of these parameters were requested at the same time. The extraction procedure required at least $300 \mu \mathrm{L}$ of whole blood (plus $200 \mu \mathrm{L}$ of dead volume) and was based on a detergent and guanidium thiocyanate lysis with the use of magnetic microparticles to isolate nucleic acids. A non-infectious linearized plasmid was used as internal inhibition control and was added to each sample within the mlysis $_{\mathrm{DNA}}$ buffer. The Abbott RealTime CMV Control kit was composed of a negative sample and a positive one while for the EBV test a negative control and two positive ones (low and high) must be included in the calibration run. Determinations of the viral loads were calculated using calibration curves established via 2 points in replicates of three and expressed in $\mathrm{IU} / \mathrm{mL}$ or $\log _{10} \mathrm{IU} / \mathrm{mL}$ for both tests but also in copies/mL or $\log _{10}$ copies/mL for the CMV assay only. These curves stored in the software were valid for a period of maximum 6 months. The announced limits of detection for the Abbott whole blood assays were respectively $62 \mathrm{IU} /$ $\mathrm{mL}\left(1.79 \log _{10} \mathrm{IU} / \mathrm{mL}\right)$ for the CMV test and $150 \mathrm{IU} / \mathrm{mL}\left(2.18 \log _{10} \mathrm{IU} /\right.$ $\mathrm{mL}$ ) for the EBV assay. In both cases, the lower limits of quantification were equivalent to the limit of detection of these viruses.

\section{4. $C M V$ and $E B V$ conversion factors}

For the EBV Diagenode assay, results were expressed in copies/mL only and there was no conversion factor provided by the manufacturer while for the EBV Abbott assay, results were provided in IU/mL only. We have thus established a copy-to-IU conversion factor for the EBV Diagenode assay using the $1^{\text {st }}$ WHO International Standard for EBV for Nucleic Acid Amplification Techniques (IS), in order to compare these results with those obtained on the Abbott platform. The conversion factor was established based on Semenova et al. protocol and was the geometric mean of 16 individual viral loads determination of a range of dilutions ( 4 sets of 4 dilutions above the LOQ) in negative whole blood from the EBV WHO IS and the given value of this International Standard (Semenova et al., 2016). Two different lots of amplification reagents were used for this. The results in copies/mL have to be multiplied by this conversion factor to obtain those results in $\mathrm{IU} / \mathrm{mL}$. The same procedure was used with the $1^{\text {st }}$ WHO International Standard for CMV for Nucleic Acid Amplification Techniques to calculate the copy to IU conversion factor for the Abbott CMV and Diagenode assays and to compare them to those proposed by the manufacturers.

\subsection{Evaluation of the analytical performances}

The analytical performances of theses assays were assessed using WHO International Standards and clinical samples. The WHO International Standards were reconstituted in $1 \mathrm{ml}$ nuclease free water to achieve a concentration of $5.10^{6} \mathrm{IU} / \mathrm{mL}$. Serial dilution ranging from 5.3 to $0.3 \log _{10} \mathrm{IU} / \mathrm{mL}$ of these WHO controls were performed in negative whole blood samples. EBV and CMV status of these negative whole blood samples were previously checked on both platforms used 
in this study. These dilutions were tested in parallel on both system in at least replicates of 4 , at different times, to determine the sensitivity, the lower limit of quantification (LLQ), the accuracy and the precision of the CMV and EBV assays. We defined the sensitivity and the LLQ as the lowest viral concentration detected or quantified in $100 \%$ of the replicates tested respectively. The mean differences between the theoretical viral loads for each WHO IS dilution and those measured from the highest concentration to the LLQ on the systems were calculated in order to evaluate the accuracy of both systems. The precision of these assays was reflected by the mean of the standard deviations (SD) calculated for each replicated single point. Raw data obtained during the validation procedure with the WHO IS are available here [dataset] (Bontems et al., 2019).

\subsection{Statistics}

All statistical analyses were performed with the $\mathrm{R}$ program version 3.3.2 from the R Foundation for Statistical Computing Platform (R Core Team (2016), n.d.). The linearity of the relation between the theoretical concentration of the WHO International Controls and the Ct values obtained for the different real-time PCR as a quality control of the preparation of the dilution curves was evaluated with this program by the calculation of a coefficient of determination for each curves $\left(\mathrm{r}^{2}\right)$. The degree of agreement between the measured viral loads in positive samples tested on both platforms was evaluated with the Spearman's rank correlation coefficient $\left(\mathrm{r}_{\mathrm{s}}\right)$. The normality of quantitative data was investigated graphically and using the Shapiro test. The pairwise $t$-test was used to calculate and to examine the relevance of the differences within the mean values in positive samples obtained with both platforms for the tests used as well as to define a 95\% confidence interval (CI) for this test. In the statistical hypothesis testings performed in this study, the significance level was set to 0.05 (5\%).

\section{Results}

\subsection{Comparison of CMV analytical performances using WHO International Standards (WHO IS)}

The results of this validation unambiguously showed a better sensitivity (defined as a $95 \%$ detection rate) when the CMV viral load is measured on the $m 2000$ platform rather than on our routine Starlet/ Diagenode system: the lowest CMV concentration detected (LLD) was $1.11 \log _{10} \mathrm{IU} / \mathrm{mL}$ for the Abbott CMV assay and $3.20 \log _{10} \mathrm{IU} / \mathrm{mL}$ for the CMV Starlet/Diagenode. The lower limit of quantification (LLQ) was also better with the CMV Abbott assay $\left(2.51 \log _{10} \mathrm{IU} / \mathrm{mL}\right.$ vs 3.20 $\log _{10} \mathrm{IU} / \mathrm{mL}$ ). The difference between the theoretical viral loads using WHO IS dilutions and those measured on the systems were compared in order to evaluate the accuracy of both system: in the linear range tested, the viral loads were slightly underestimated with the CMV Abbott assay $\left(-0.25 \log _{10} \mathrm{IU} / \mathrm{mL} ; \mathrm{SD}=0.32\right)$ while they were rather overestimated when the Starlet/Diagenode system was used $\left(+0.48 \log _{10} \mathrm{IU} / \mathrm{mL}\right.$; $\mathrm{SD}=0.15$ ) (Fig. 1). The precision of these assays, reflected by the means of the standard deviations (SD) calculated for each replicated single point, was better with the Abbott RealTime platform $\left(0.16 \log _{10}\right.$ $\mathrm{IU} / \mathrm{mL}+/-4.82 \%)$ than using our routine CMV Starlet/Diagenode protocol for the CMV PCR $\left(0.33 \log _{10} \mathrm{IU} / \mathrm{mL}+/-7 \%\right)$. We also compared the observed variations in the $\mathrm{Ct}$ values of the respective internal controls used in the two tests and we showed that this variation was also lower on the Abbott platform $(\mathrm{CV}=0.99 \%)$ than using the Starlet/Diagenode system ( $\mathrm{CV}=2.4 \%$ ). For the Abbott CMV assay, the manufacturer has established a unique copy-to-IU conversion factor for both plasma and whole blood matrix ( 1 copy $=1.56 \mathrm{IU})$. In this study, CMV WHO IS were used to evaluate this conversion factor and it was established that 1 copy $=2.5 \mathrm{IU}$. For the Diagenode CMV assay, the manufacturer has established a copy-to-IU conversion factor using also the CMV WHO IS (NIBSC code 09/162) where 1 copy $=1.2 \mathrm{IU}$. In our study, the use of this CMV IS allowed us to established that 1 copy $=$ $0.41 \mathrm{IU}$.

\subsection{Comparison of EBV analytical performances using WHO International Standards}

Abbott EBV results are reported in International Units/mL but in the Diagenode test, results are delivered in copies $/ \mathrm{mL}$. To be able to fully confront them, we used the WHO IS standards to determine a copy to IU conversion factor for the Diagenode EBV assay. This conversion factor was established to be 1 copy $=0.77 \mathrm{IU}$ and was used to convert all viral loads expressed in copies/mL with the EBV Starlet/Diagenode platform to IU/mL. Thus, the commercially announced LLD of 822 copies $/ \mathrm{mL}$ was $633 \mathrm{IU} / \mathrm{mL}\left(2.8 \log _{10} \mathrm{IU} / \mathrm{mL}\right)$. Using decreasing concentrations of the EBV WHO IS spiked in negative whole blood we showed that the measured LLD for the Diagenode assay was better than announced (65 $\mathrm{IU} / \mathrm{mL}$ or $1.81 \log _{10} \mathrm{IU} / \mathrm{mL}$ ) and similar to the Abbott EBV assay while the LLQ with the Starlet/Diagenode method was better (1.81 $\log _{10}$ IU/ $\mathrm{mL}$ ) than with the Abbott one (2.51 $\log _{10} \mathrm{IU} / \mathrm{mL}$ ) (Fig. 1). As for the CMV assay, the EBV Abbott assay exhibited a slight underestimation of the viral loads $\left(-0.21 \log _{10} \mathrm{IU} / \mathrm{mL} ; \mathrm{SD}=0.21\right)$, while the viral loads obtained on the Starlet/Diagenode platform were slightly overestimated, especially at low viral loads, with an accuracy for this test of $0.19 \log _{10} \mathrm{IU} / \mathrm{mL}(\mathrm{SD}=0.23)$. The precision of these assays was also better with the Abbott RealTime platform $\left(0.19 \log _{10} \mathrm{IU} / \mathrm{mL}+/-\right.$ $5.18 \%$ ) than using our routine CMV Starlet/Diagenode protocol for the EBV PCR $\left(0.43 \log _{10} \mathrm{IU} / \mathrm{mL}+/-11.83 \%\right)$.

\subsection{Comparison of CMV analytical performances using clinical samples and $Q C M D$}

Eighty-six whole-blood clinical samples coming from our institution were challenged on both systems. Out of these samples, 38 (44\%) were detected using our routine CMV Starlet/Diagenode system including 15 samples (17\%) under the announced limit of quantification (LOQ) and 23 quantified (quantification rate $=27 \%$ ) (Fig. 2). When these 86 samples were proceeded on the Abbott $m 2000$ platform, 48 (56\%) were detected using this CMV assay including 6 samples (7\%) under the limit of quantification of the test while the quantification rate was $49 \%$ (42 samples) with this method. Among the discrepancy results, 12 samples quantified by the Abbott system (viral loads ranging from 96 to 1207 $\mathrm{IU} / \mathrm{mL})$ were under the LOQ $(820 \mathrm{IU} / \mathrm{mL})$ of the CMV Diagenode test and 8 samples were only detected with the CMV Abbott assay (viral loads ranging from 78 to $312 \mathrm{IU} / \mathrm{mL}$ ). Out of these 20 samples, 10 of them quantified by the Abbott system had a viral load greater than our locally defined treatment threshold for CMV (1000 copies/mL) suggesting that the corresponding patients would have been considered for treatment if the Abbott system had been used routinely at that moment with the same threshold.

Twenty-two samples (25\%) were quantified using both methods and the statistical analysis of the results showed that these methods were correlated $\left(p=0.0002, r_{s}=0.72\right)$. However, the mean difference (bias) between both test was $0.79 \log _{10} \mathrm{IU} / \mathrm{mL}$, indicating that the viral loads measured with the Starlet/Diagenode system were on average $0.79 \log _{10} \mathrm{IU} / \mathrm{mL}$ higher than those measured with the CMV Abbott assay, and this difference was statistically significant (p-value $=$ $6.10^{-6}$ ) (Fig. 3). As a consequence, 5 of the 22 samples quantified by the Starlet/Diagenode system had a viral load above the treatment threshold but fell below this threshold when quantified using the Abbott system.

To address the signification of this difference in terms of follow-up of patients, successive samples were collected at different times and the CMV viral load measured using those two techniques. The graphicallypresented results showed that replication kinetics of the viral load measured for these patients were similar using both methods but that the sensitivity of the CMV Abbott assay was often better for low viral 

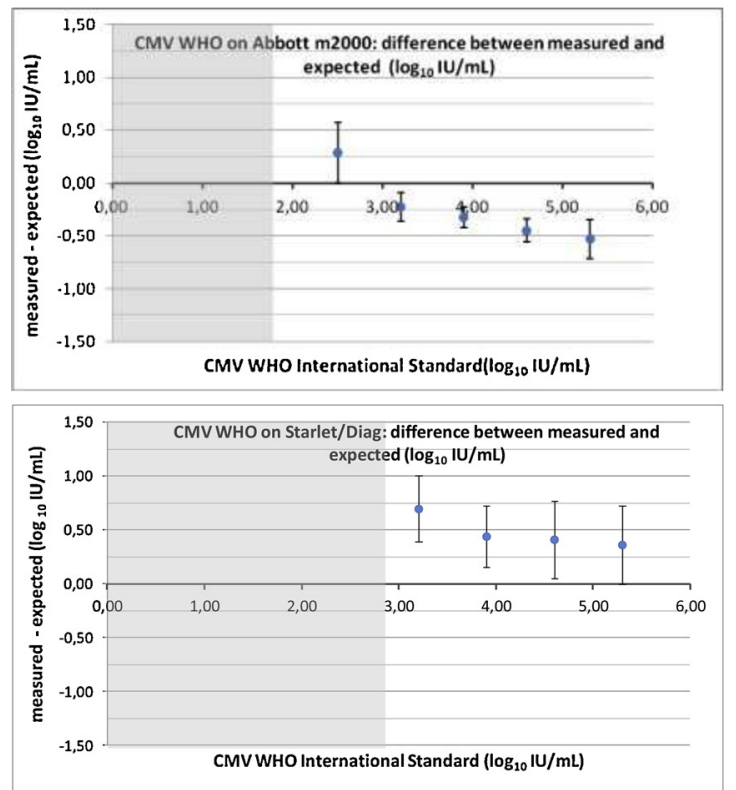
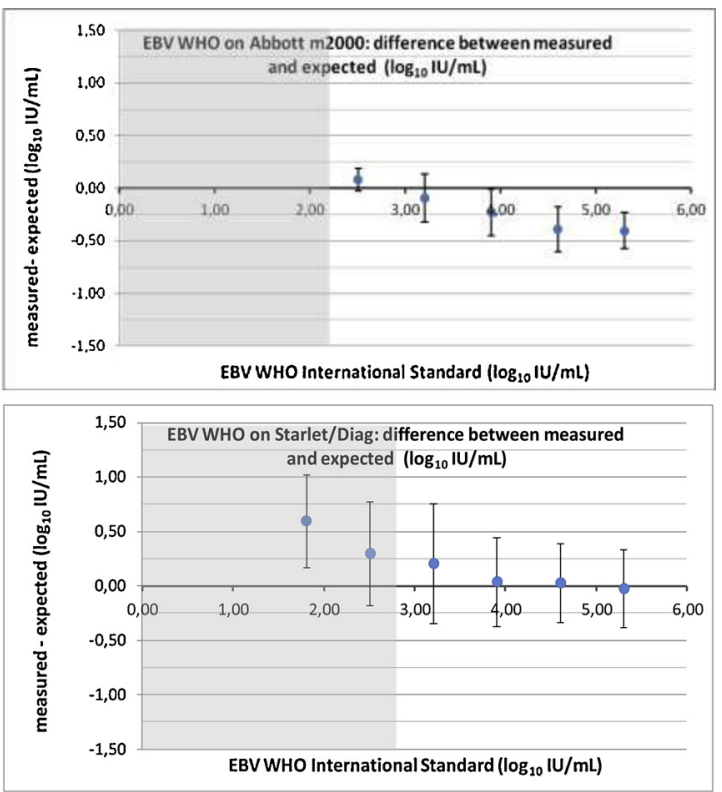

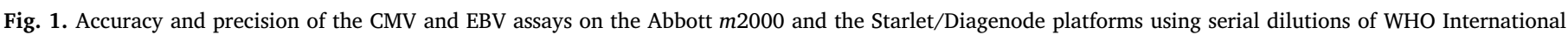

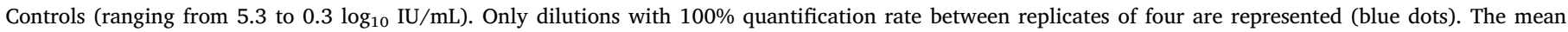

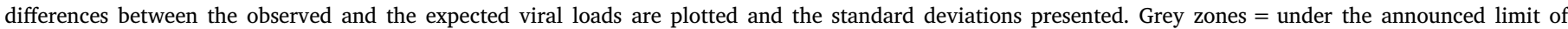
quantification (LOQ) of the tests.

loads while the viral load peaks were more pronounced when measured with the Starlet/Diagenode system (Fig. 4).

These observations were also confirmed using external controls from the Quality Controls for Molecular Diagnostics (QCMD) organization: out of the 15 samples tested, all were correctly evaluated with the Abbott assay (100\% detection rate and all viral loads measured felt within 1 Standard Deviation (SD) of the consensus values) while using the Starlet/Diagenode system 2 low positive samples were not detected,
4 quantified samples had a measured viral load above 1 SD and 1 quantified sample had a viral load above 2SD of the mean consensus value confirming the overestimation of the viral loads when the Starlet/ Diagenode protocol was used (Table 1 ).

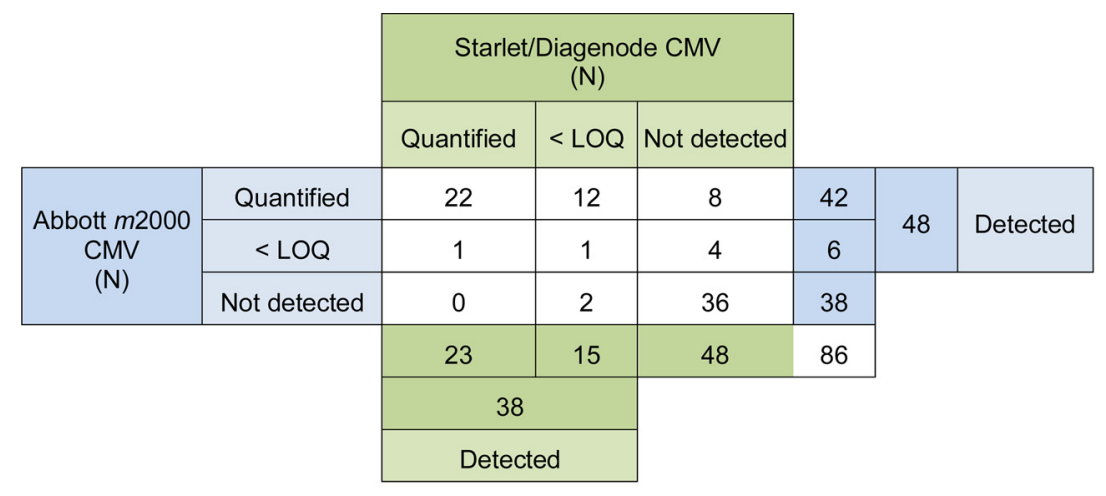

\begin{tabular}{|c|c|c|c|c|c|c|c|}
\hline & & \multicolumn{3}{|c|}{$\begin{array}{l}\text { Starlet/Diagenode EBV } \\
(\mathrm{N})\end{array}$} & & & \\
\hline & & Quantified & $<\mathrm{LOQ}$ & Not detected & & & \\
\hline \multirow{3}{*}{$\begin{array}{l}\text { Abbott } m 2000 \\
\text { EBV } \\
\text { (N) }\end{array}$} & Quantified & 31 & 10 & 1 & 42 & \multirow{2}{*}{54} & \multirow{2}{*}{ Detected } \\
\hline & $<L O Q$ & 3 & 5 & 4 & 12 & & \\
\hline & Not detected & 0 & 3 & 29 & 32 & & \\
\hline & & 34 & 18 & 34 & 86 & & \\
\hline & & \multicolumn{2}{|c|}{52} & & & & \\
\hline & & \multicolumn{2}{|c|}{ Detected } & & & & \\
\hline
\end{tabular}

Fig. 2. CMV and EBV detection and quantification in clinical samples using the Abbott $m 2000$ vs the Starlet/Diagenode system. $N=$ number of samples. $<$ LOQ $=$ under the limit of quantification of the assay. 

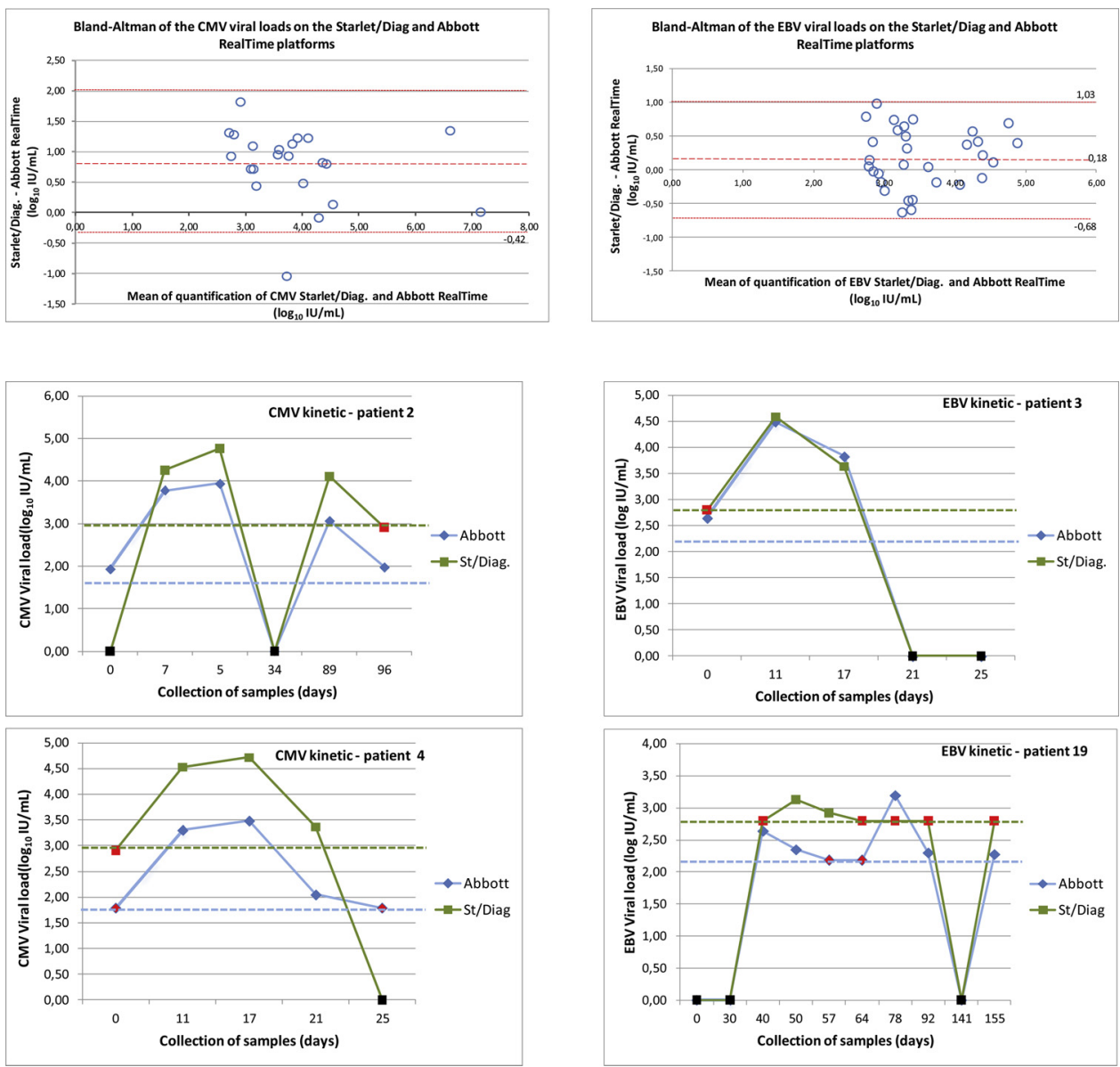

Fig. 3. Bland-Altman analysis of the CMV and EBV assays performed on the Starlet/ Diagenode and the Abbott RealTime systems for the 22 (CMV) and 31 (EBV) positive clinical samples. Agreement between two methods is met if $\geq 95 \%$ of the samples are found between $+/-1.96$ SD (dotted lines) from the mean difference (bias; dashed line) (Bland and Altman, 2007). CMV (21/22; 95.4\%) and EBV $(33 / 33 ; 100 \%)$ assays met this criterion.

Fig. 4. Kinetics of CMV and EBV viral loads in patients follow-up. The dotted colored lines are the limits of quantification (LOQ) of the tests (blue $=$ Abbott $m 2000, \quad$ green $=$ Starlet $/$ Diagenode). Samples with CMV or EBV detected but under the LOQ are represented by red squares (for the Starlet/Diagenode test) or red diamond (for the Abbott assay) on the corresponding dotted line. Black spots represent samples with an undetected viral load.

\subsection{Comparison of EBV analytical performances using clinical samples and $Q C M D$}

For the evaluation of the Abbott EBV assay, 86 samples from 46 patients were collected and tested in parallel with both systems. Out of these 86 samples, $52(60.5 \%)$ were detected with 34 samples quantified (39.5\%) and $18(21 \%)$ under the commercially announced LOQ with the Starlet/Diagenode system while 54 were detected (63\%) with a quantification rate of $49 \%$ (42 samples) while 12 samples (14\%) were under the LOQ with the Abbott EBV assay. Among the discrepancy samples, 10 samples were quantified by the Abbott assay (viral loads ranging from 189 to $1570 \mathrm{IU} / \mathrm{mL}$ ) but were under the announced LOQ of the Diagenode assay (663 IU/mL). Moreover, 1 sample was not detected by the Starlet/Diagenode system but quantified using the Abbott assay with a detected viral load of $1090 \mathrm{IU} / \mathrm{mL}$ (see Fig. 2). Fourteen samples quantified by the Abbott system had a viral load greater than our locally defined treatment threshold for EBV (1000 copies $/ \mathrm{mL}$ ), unlike with the Starlet/Diagenode one where most of these samples were under the LOQ $(820 \mathrm{IU} / \mathrm{mL})$. Conversely, 4 samples had a viral load under the treatment threshold when measured on the Abbott platform, unlike with the Starlet/Diagenode system.

Out of the 86 samples tested, 31 (36\%) were quantified using both methods and the calculated correlation coefficient has indicated that both methods were correlated $\left(r_{s}=0.75\right.$, $p$-value $\left.<0,0001\right)$. The mean difference between both test was $0.18 \log _{10} \mathrm{IU} / \mathrm{mL}$ indicating that the viral loads measured with the Starlet/Diagenode system were on average slightly higher than those measured with the EBV Abbott assay and this difference was statistically significant (p-value $=0.03$ ) (Fig. 3).

The follow-up of EBV among positive patients was conducted and it can be shown on the representative patients presented on Fig. 4 that the EBV viral load kinetics were rather similar when performed on both systems. This was also confirmed using external controls from the Quality Controls for Molecular Diagnostics (QCMD) organization: out of the 10 samples tested, all were correctly evaluated with both methods ( $100 \%$ detection rate). One sample had a measured viral load above 1 SD of the consensus value with the Abbott assay and two with the Starlet/Diagenode system (Table 1).

\subsection{Comparison of the workflows using the Abbott EBV/CMV maxCycle and the Starlet/Diagenode protocols}

The workflows and the turnaround time (TAT) to process WB samples were evaluated on the automated Abbott $m 2000$ platform using the Abbott Realtime CMV/EBV maxCycle protocol and compared to the Starlet/Diagenode system. In both cases, CMV and EBV assays can be processed in a single run but two separate extractions must be performed on the m2000sp on a split sample (or on duplicated primary samples) if both CMV and EBV viral loads are requested for a single patient. To evaluate this, the overall process was divided in 5 steps and the mean time to complete each step, reported per sample, was measured during 4 runs of 50\% EBV and 50\% CMV samples by distinguishing manual from automated procedures (Fig. 5). Our results indicated that the TAT per sample was slightly increased $(+11.5 \%)$ using the Abbott platform $(10.60+/-0.14 \mathrm{~min} / \mathrm{sample}$ vs. $9.50+/-$ $0.17 \mathrm{~min} / \mathrm{sample}$ ) rather than the Starlet/Diagenode procedure. The main reason was that the Abbott platform could only handle a maximum of 48 samples (including controls) at the same time while 80 samples (including controls) can be processed using the Starlet/Diagenode protocol in a single run. However, we clearly observed that there was a reduction of about $62.8 \%$ of the technical hands-on time (HAT) with the Abbott system compared to the Starlet/Diagenode one. The number of manual interventions was much higher with the Starlet/ 
Table 1

QCMD CMV and EBV challenges. The EQA (External Quality Assessment) consensus viral loads as well as the standard deviations (SD) are indicated for each sample either in copies $/ \mathrm{mL}$ or in IU $/ \mathrm{mL} . \Delta=$ difference between measured and expected viral loads, Ndt $=$ Not detected.

\begin{tabular}{|c|c|c|c|c|c|c|c|c|c|c|c|}
\hline \multicolumn{5}{|l|}{ QCMD CMV } & \multicolumn{3}{|c|}{ Starlet/Diagenode } & & \multicolumn{3}{|l|}{ Abbott } \\
\hline & & \multicolumn{2}{|c|}{$\begin{array}{l}\text { EQA Consensus } \\
\log _{10} \operatorname{cop} / \mathrm{mL}\end{array}$} & SD & \multicolumn{3}{|c|}{$\begin{array}{l}\text { Results } \\
\log _{10} \operatorname{cop} / \mathrm{mL}\end{array}$} & & \multicolumn{2}{|c|}{$\begin{array}{l}\text { Results } \\
\log _{10} \operatorname{cop} / \mathrm{mL}\end{array}$} & $\Delta$ \\
\hline CMVWB15C1-01 & & \multicolumn{2}{|l|}{2,17} & 0,62 & \multicolumn{2}{|l|}{ Ndt } & \multicolumn{2}{|l|}{ / } & \multicolumn{2}{|l|}{1,99} & $-0,17$ \\
\hline CMVWB15C1-02 & & \multicolumn{2}{|l|}{3,05} & 0,44 & \multicolumn{2}{|l|}{3,00} & \multicolumn{2}{|l|}{$-0,05$} & \multicolumn{2}{|l|}{2,69} & $-0,36$ \\
\hline CMVWB15C1-03 & & \multicolumn{2}{|l|}{3,08} & 0,42 & \multicolumn{2}{|l|}{3,28} & \multicolumn{2}{|l|}{0,21} & \multicolumn{2}{|l|}{2,81} & $-0,26$ \\
\hline CMVWB15C1-04 & & \multicolumn{2}{|l|}{-} & - & \multicolumn{2}{|l|}{ Ndt } & \multicolumn{2}{|l|}{-} & \multicolumn{2}{|l|}{ Ndt } & - \\
\hline CMVWB15C1-05 & & \multicolumn{2}{|l|}{2,99} & 0,37 & 2,79 & & $-0,20$ & & 2,91 & & $-0,08$ \\
\hline CMVWB15C2-01 & & 2,64 & & 0,36 & 2,22 & & $-0,42$ & & 2,30 & & $-0,34$ \\
\hline CMVWB15C2-02 & & 2,05 & & 0,39 & Ndt & & / & & 1,78 & & $-0,27$ \\
\hline CMVWB15C2-03 & & 3,56 & & 0,29 & 4,16 & & 0,61 & & 3,35 & & $-0,21$ \\
\hline CMVWB15C2-04 & & - & & - & Ndt & & - & & Ndt & & - \\
\hline CMVWB15C2-05 & & 2,90 & & 0,36 & 3,48 & & 0,58 & & 2,77 & & $-0,13$ \\
\hline CMVWB16C1-01 & & 2,92 & & 0,41 & 3,09 & & 0,17 & & 3,11 & & 0,19 \\
\hline CMVWB16C1-02 & & - & & - & Ndt & & - & & Ndt & & - \\
\hline CMVWB16C1-03 & & 2,82 & & 0,45 & 3,29 & & 0,47 & & 2,75 & & $-0,07$ \\
\hline CMVWB16C1-04 & & 2,77 & & 0,50 & 2,97 & & 0,20 & & 2,68 & & $-0,09$ \\
\hline CMVWB16C1-05 & & 2,40 & & 0,45 & 2,88 & & 0,48 & & 2,46 & & 0,06 \\
\hline QCMD EBV & & & & Starlet & & $\mathrm{QCM}$ & & & & Abbott & \\
\hline & $\begin{array}{l}\text { EQA } \\
\log _{10}\end{array}$ & $\begin{array}{l}\text { onsensus } \\
\mathrm{cop} / \mathrm{mL}\end{array}$ & SD & $\begin{array}{l}\text { Result } \\
\log _{10}\end{array}$ & $\Delta$ & $\begin{array}{l}\text { EQA } \\
\log _{10}\end{array}$ & $\begin{array}{l}\text { sensus } \\
\text { nL }\end{array}$ & SD & & $\begin{array}{l}\text { Results } \\
\log _{10} \mathrm{IU} / \mathrm{mL}\end{array}$ & $\Delta$ \\
\hline EBVWB15C2-01 & 3,49 & & 0,46 & 3,85 & 0,36 & 3,67 & & 0,12 & & 3,64 & $-0,03$ \\
\hline EBVWB15C2-02 & 3,08 & & 0,44 & 3,23 & 0,15 & 3,19 & & 0,10 & & 3,33 & 0,14 \\
\hline EBVWB15C2-03 & 3,99 & & 0,38 & 4,19 & 0,19 & 4,15 & & 0,14 & & 4,12 & $-0,03$ \\
\hline EBVWB15C2-04 & - & & - & - & - & - & & - & & - & - \\
\hline EBVWB15C2-05 & 2,73 & & 0,54 & 2,97 & 0,24 & 2,56 & & 0,15 & & 2,43 & $-0,13$ \\
\hline EBVWB16C1-01 & 3,51 & & 0,44 & 4,11 & 0,60 & 3,74 & & 0,12 & & 3,65 & $-0,09$ \\
\hline EBVWB16C1-02 & 3,22 & & 0,61 & 3,78 & 0,56 & 2,65 & & 0,46 & & 2,22 & $-0,43$ \\
\hline EBVWB16C1-03 & - & & - & - & - & - & & - & & - & - \\
\hline EBVWB16C1-04 & 2,40 & & 0,57 & 2,48 & 0,08 & 2,18 & & 0,00 & & 2,18 & 0,00 \\
\hline EBVWB16C1-05 & 3,55 & & 0,43 & 4,00 & 0,45 & 3,79 & & 0,14 & & 3,72 & $-0,07$ \\
\hline
\end{tabular}

Diagenode system, meaning that more technical resources were required to complete these tasks. It was noticeable for the mastermix preparation step, its addition to the DNA extracts as well as for the data management, including the internal controls analysis and the transfer of the results to the LIS system.

\section{Discussion \& conclusions}

In this study, we evaluated the CMV and EBV RealTime PCR assays proposed by Abbott on the $m 2000$ platform using the CMV/EBV maxCycle protocol allowing the execution of these two assays in a single run. Our reference technique for this evaluation was our routinely-used two-steps procedure consisting of a NucleoMag ${ }^{\circledR}$ (MachereyNagel) whole-blood DNA extraction automated on a STARlet platform (Hamilton) followed by a manually processed quantitative real time PCR using CMV and EBV assays (Diagenode). The search for a more automated solution for these assays was motivated by the desire to improve the performances of our routinely-used assays but also to reduce the technician's hands-on time. Several studies have already been published in this context to compare the performances of manually processed and automated real-time PCR solutions available to detect or quantified different pathogens in clinical samples and/or WHO standards (Engelmann et al., 2019, 2018; Furione et al., 2012; Vinuesa et al., 2017).

We showed that the analytical performances of the Abbott CMV and EBV assays were satisfying and overall improved compared to our routinely-used method, with a variability of the viral loads measured lower with the Abbott assays (mean of $\mathrm{SD}=0.16 \log _{10} \mathrm{IU} / \mathrm{mL}$ vs 0.33 $\log _{10} \mathrm{IU} / \mathrm{mL}$ for CMV and $0.19 \log _{10} \mathrm{IU} / \mathrm{mL}$ vs $0.43 \log _{10} \mathrm{IU} / \mathrm{mL}$ for EBV), in accordance to the performances announced by the manufacturer (inter-assay mean of SD $=0.09 \log _{10} \mathrm{IU} / \mathrm{mL}$ and $0.14 \log _{10} \mathrm{IU} /$
$\mathrm{mL}$ respectively; see package inserts) and also in agreement with other studies for CMV (Schnepf et al., 2013) and EBV (Salmona et al., 2016). To our knowledge, this study is the first one evaluating the accuracy, as well as the sensitivity, of the Abbott RealTime EBV assay using WHO IS. Concerning the accuracy of the CMV Abbott RealTime assay, Schnepf et al. have evaluated it using QCMD controls as being also slightly lower than expected with a mean difference between measured and expected values of $-0.26 \log _{10}$ copies/mL (Schnepf et al., 2013) while Tsai et al. observed a bias of $0.141 \log _{10} \mathrm{IU} / \mathrm{ml}$ when CMV WHO IS were used, this late being performed with the plasma extraction protocol unlike our study (Tsai et al., 2016). The results obtained at the QCMD external controls challenges for CMV and EBV were also satisfying, reinforcing the idea that both tests are reliable and accurate. It must be also noted that during this validation procedure, no clinical sample tested failed using the Abbott platform (e.g. internal control out of range). With the Starlet/Diagenode system we had a measured failure rate of $4 \%$ (data not shown), but mostly due to pipetting errors. The follow-up of several CMV and EBV positive patients showed that the kinetics of the viral loads were rather similar, but with a marked overestimation of the CMV load when the Starlet/Diagenode system was used. This can have an impact on the patient care and must be considered if they are based on locally defined treatment thresholds.

Expression of the viral loads in International Units is more and more advised for clinical laboratories: in a survey conducted by the European Study Group of Infections in Immunocompromised Hosts (ESGICH), data collected have clearly revealed that if a large part of the centers questioned systematically use quantitative real-time PCR for CMV monitoring (99.4\%), only $30 \%$ of them reported the DNA loads in IU/ $\mathrm{mL}$ while the majority $(63.6 \%)$ reported it in copies/mL (Navarro et al., 2017). This study has also revealed that most clinicians questioned $(82.5 \%)$ started preemptive antiviral treatment when CMV DNA load 


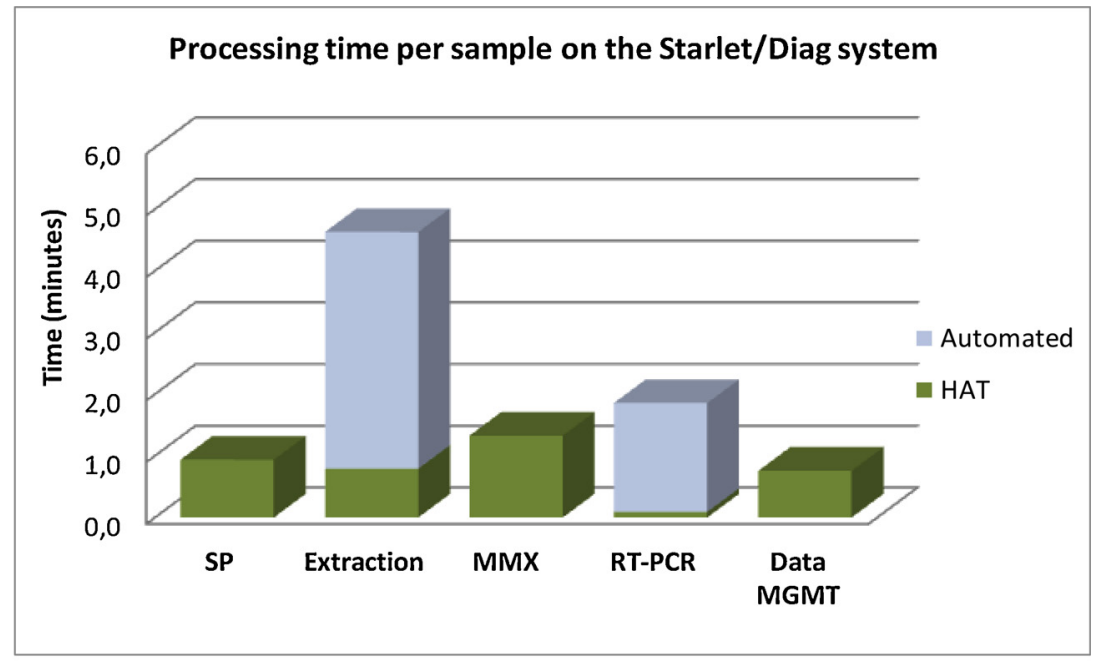

Processing time per sample on the Abbottm2000 system

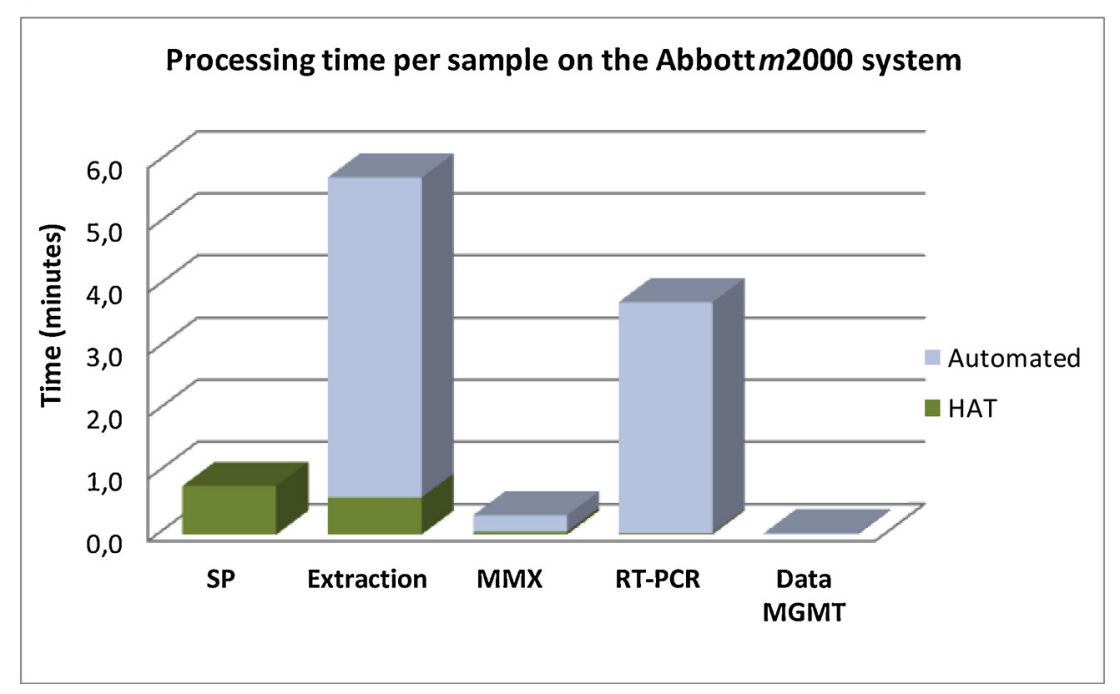

Fig. 5. Comparison of the workflows for the CMV and EBV viral load determination using the Abbott EBV/CMV maxCycle and the Starlet/Diagenode protocols by distinguishing manual from automated procedures. The mean time for each step was related per sample. SP = samples process, including samples sorting, aliquoting, tube labeling and the generation of the working lists. Extraction = extraction procedure including the pre- and the post-run maintenances, reactive, disposables and samples loadings. MMX = Mastermix preparation and addition to the DNA samples. Data MGMT = Data management, including the controls analysis and the LIS transfer. HAT $=$ technical hands-on time. exceeded a predefined and locally validated cut-off. This late varies from 100 to $>100.000 \mathrm{IU} / \mathrm{mL}$ when whole blood specimens are used, with a commonly used $1000 \mathrm{CMV}$ DNA IU/mL threshold. As a consequence, CMV load determination must be carried out with the same assay, on the same matrix and in the same center when patient monitoring is performed. It also highlights the importance of a constant dialogue with the clinicians when such a change of method is being considered by a clinical laboratory. In our institution, a careful followup of the patients was made during several weeks after the routine implementation of the Abbott platform and new therapeutic thresholds were defined in agreement with the clinicians and based on our local experience.

The Abbott RealTime CMV/EBV maxCycle protocol provides results in $\mathrm{IU} / \mathrm{mL}$ or in copies/mL for the CMV assay but only in $\mathrm{IU} / \mathrm{mL}$ for the EBV one, unlike the version 1.0 of this assay. We have calculated in this study, although with a limited number of replicates, a copy-to-IU conversion factor for the CMV assay using the WHO IS diluted in whole blood and we have shown that it was slightly higher (1 copy $=2.5 \mathrm{IU}$ ) than the one provided by the manufacturer for the plasma and the whole blood (WB) specimen (1 copy $=1.4 \mathrm{IU})$. Other studies have determined more divergent conversion factors for the same assay using also WHO IS in WB as reference: Schnepf et al. have calculated a conversion factor where 1 copy $=0.46 \mathrm{IU}$ when the WHO IS was diluted in whole blood and 1 copy $=0.86 \mathrm{IU}$ when it was diluted in PBS while Furione et al. have calculated a conversion factor where 1 copy $=7.69$ IU in WB (Furione et al., 2012; Schnepf et al., 2013). We have also calculated a conversion factor for the Diagenode CMV assay (1 copy =
$0.41 \mathrm{IU}$ ) and showed that it was divergent to the one provided by the manufacturer (1 copy $=1.2 \mathrm{IU}$ ). The origin of these discrepancies could be found in the absence of a detailed and consensual protocol to calculate the conversion factor according to the assay as well to the matrix used (Schnepf et al., 2013) but also in the nature of the standards used. The absence of commutable International Standards (IS) prevented for many years the establishment of clinical thresholds for therapeutic decisions due to the high variability observed between the different techniques or matrix used for the viral loads determination and to the absence of harmonization of these tests (Caliendo et al., 2009; Wolff et al., 2009). EBV (Fryer et al., 2016b) and CMV(Fryer et al., 2016a) WHO International Standards were developed to meet the needs expressed in this way in the guidelines and the recommendations made by the healthcare professionals (Andrews et al., 2011; Gulley and Tang, 2010; Heemann et al., 2011; Kim et al., 2017; Kotton et al., 2013; Navarro et al., 2017; Torre-Cisneros et al., 2016; Wattles et al., 2017). However, the commutability of the EBV (Abeynayake et al., 2014; Ruf and Wagner, 2013; Tang et al., 2016) and CMV (Fryer et al., 2016c; Hayden et al., 2015, 2013) WHO IS was examined and questioned. For instance, Preiksaitis et al. conducted a study using 10 different qPCR assays calibrated to the IS and they determined the viral loads of serial IS dilutions and a blinded panel of CMV positive and negative clinical samples. They reported that variations were somewhat limited by the use of the IS as reference to calibrate the assays, but a significant variability was still observed mostly for clinical samples. The origin of this variability is still not well-defined, linked to the size of the amplicons detected by the different assays but mostly multifactorial 
(Preiksaitis et al., 2016).

One of the stated goals of lab automation is to save time to increase either the productivity of the laboratories or to dedicate technical resources to more specific and/or valuable tasks. In this study we have estimated that the use of the Abbott RealTime CMV/EBV maxCycle protocol increases the turnaround time (TAT) of about $11.5 \%$ compared to our previous system. The main reason is that the Abbott platform can only process a maximum of 48 samples (including controls) at the same time which is nearly half of the samples that can be processed using the Starlet/Diagenode protocol. Moreover, the protocols for the DNA extraction as well as for the PCR are longer than with the Starlet/ Diagenode system. However, we observed a technician hands-on time reduction of more than $60 \%$ using the Abbott platform due to the high automation of this system. It is noticeable for the mastermix preparation and assembly as well as for the data management processes. It must be noted that if the Abbott RealTime CMV/EBV maxCycle protocol allows the extraction of both CMV and EBV in the same run, two separate extractions must be performed on a split sample (or on duplicated primary samples) if both CMV and EBV viral loads are requested for a single patient. Interestingly, the CMV/EBV maxCycle protocol also uses the Abbott mPLUS feature that allows the tracking of the number of tests used as well as the tests remaining within an amplification pack. This feature greatly increases the flexibility of the Abbott $m 2000$ platform (Lucic et al., 2013).

In conclusion, the results presented in this study indicate that the Abbott RealTime CMV/EBV maxCycle protocol is functional, reliable and accurate when these assays are performed on blood samples, that it allows a reduction of the technical hands-on time, a significant increase in the quality of the results and their delivery in International Units for both assays.

\section{Funding/Disclosure}

This research did not receive any specific grant from funding agencies in the public, commercial or not-for-profit sectors. The Abbott CMV and EBV assays for this study were provided by Abbott Molecular but the authors declare to have kept their independency in the conduction, design, analysis and discussion of this study. None of the authors are or were member of the Abbott Company.

\section{References}

Abeynayake, J., Johnson, R., Libiran, P., Sahoo, M.K., Cao, H., Bowen, R., Allen Chan, K.C., Le, Q.T., Pinsky, B.A., 2014. Commutability of the epstein-barr virus WHO international standard across two quantitative PCR methods. J. Clin. Microbiol. 52, 3802-3804. https://doi.org/10.1128/JCM.01676-14.

Andrews, P.A., Emery, V.C., Newstead, C., 2011. Summary of the British transplantation society guidelines for the prevention and management of CMV disease after solid organ transplantation. Transplantation 92, 1181-1187. https://doi.org/10.1097/TP. 0b013e318235c7fc.

Bland, J., Altman, G., 2007. Measuring agreement in method comparison studies - a review. Adv. Rank. Sel. Mult. Comp. Reliab. 2802, 215-244. https://doi.org/10. 1007/0-8176-4422-9_13.

Bontems, S., Hayette, M.-P., Descy, J., Huynen, P., Melin, P., Capraro, V., Boreux, R., Meex, C., 2019. Raw Data From the Validation of the Abbott RealTime CMV/EBV maxCycle Protocol Using WHO International Standards. n.d., Mendeley Data, v1. https://www.google.com/search? client $=$ firefox-b-d\&channel $=$ trow\& $\mathrm{q}=\mathrm{https} \% 2 \mathrm{~F}$ $\% 2 \mathrm{Fdata}$.mendeley.com $\% 2 \mathrm{Fdatasets} \% 2 \mathrm{Fgsjh} 22 \mathrm{~h} 3 \mathrm{w} 7 \% 2 \mathrm{Fdraft} \% 3 \mathrm{Fa}$ \%3De79e170ef494-4149-845c-bbbbdfd088c4.

Caliendo, A.M., Shahbazian, M.D., Schaper, C., Ingersoll, J., Abdul-Ali, D., Boonyaratanakornkit, J., Pang, X.L., Fox, J., Preiksaitis, J., Schönbrunner, E.R., 2009. A commutable cytomegalovirus calibrator is required to improve the agreement of viral load values between laboratories. Clin. Chem. 55, 1701-1710. https://doi.org/ 10.1373/clinchem.2009.124743.

Croxatto, A., Prod'hom, G., Faverjon, F., Rochais, Y., Greub, G., 2016. Laboratory automation in clinical bacteriology: what system to choose? Clin. Microbiol. Infect. 22, 217-235. https://doi.org/10.1016/j.cmi.2015.09.030.

Dauwalder, O., Landrieve, L., Laurent, F., de Montclos, M., Vandenesch, F., Lina, G., 2016. Does bacteriology laboratory automation reduce time to results and increase quality management? Clin. Microbiol. Infect. 22, 236-243. https://doi.org/10.1016/ j.cmi.2015.10.037.

Dioverti, M.V., Razonable, R.R., 2016. Cytomegalovirus. Microbiol. Spectr. 4, 1-26. https://doi.org/10.1128/microbiolspec.DMIH2-0022-2015.Correspondence.
Engelmann, I., Alidjinou, E.K., Lazrek, M., Pouillaude, J., Ogiez, J., Rose, F., Duhamel, A., Dewilde, A., Hober, D., 2019. Comparison of Two Commercial Quantitative PCR Assays for EBV DNA Detection and their Correlation with the First WHO International Standard for EBV. pp. 529-536. https://doi.org/10.1099/jmm.0.000702.

Engelmann, I., Kazali, E., Lazrek, M., Ogiez, J., Pouillaude, J., Chazard, E., Dewilde, A., Hober, D., 2018. Comparison of two commercial quantitative PCR assays and correlation with the fi rst WHO International Standard for human CMV. Diagn. Microbiol. Infect. Dis. 91, 27-33. https://doi.org/10.1016/j.diagmicrobio.2017.12. 021.

Felder, R.A., Boyd, J.C., Savory, J., Margrey, K., Martinez, A., Vaughn, D., 1988. Robotics in the clinical laboratory. Clin. Lab. Med. 8, 699-711.

Fryer, J.F., Heath, A.B., Minor, P.D., Kessler, H., Rawlinson, W., Boivin, G., Preiksaitis, J., Pang, X.-L., Barranger, C., Alain, S., Bressollette-Bodin, C., Hamprecht, K., Grewing, T., Constantoulakis, P., Ghisetti, V., Capobianchi, M.R., Abbate, I., Olivo, C., Lazzarotto, T., Baldanti, F., Inoue, N., Müller, F., Corcoran, C., Hardie, D., Prieto, J., Schuurman, R., van Loon, A., Ho, S., Hillyard, D., Hodinka, R., Louise Landry, M., Caliendo, A., Lurain, N., Sung, L., Gulley, M., Atkinson, C., Bible, J., Guiver, M., 2016a. A collaborative study to establish the 1st WHO International Standard for human cytomegalovirus for nucleic acid amplification technology. Biologicals 44 , 242-251. https://doi.org/10.1016/j.biologicals.2016.04.005.

Fryer, J.F., Heath, A.B., Wilkinson, D.E., Minor, P.D., 2016b. A collaborative study to establish the 1st WHO International Standard for Epstein-Barr virus for nucleic acid amplification techniques. Biologicals 44, 423-433. https://doi.org/10.1016/j. biologicals.2016.04.010.

Fryer, J.F., Morris, C.L., Almond, N.M., Minor, P.D., 2016c. Commutability of the first world health organization international standard for human cytomegalovirus: standard or assay. J. Clin. Microbiol. 54, 3073. https://doi.org/10.1128/JCM.01706-16.

Furione, M., Rognoni, V., Cabano, E., Baldanti, F., 2012. Kinetics of human cytomegalovirus (HCMV) DNAemia in transplanted patients expressed in international units as determined with the Abbott RealTime CMV assay and an in-house assay. J. Clin. Virol. 55, 317-322. https://doi.org/10.1016/j.jcv.2012.08.017.

Gulley, M.L., Tang, W., 2010. Using Epstein-Barr viral load assays to diagnose, monitor, and prevent posttransplant lymphoproliferative disorder. Clin. Microbiol. Rev. 23, 350-366. https://doi.org/10.1128/CMR.00006-09.

Hawker, C.D., 2007. Laboratory automation: total and subtotal. Clin. Lab. Med. 27, 749-770. https://doi.org/10.1016/j.cll.2007.07.010.

Hayden, R.T., Preiksaitis, J., Tong, Y., Pang, X., Sun, Y., Tang, L., Cook, L., Pounds, S., Fryer, J., Caliendo, A.M., 2015. Commutability of the first world health organization international standard for human cytomegalovirus. J. Clin. Microbiol. 53, 3325-3333. https://doi.org/10.1128/JCM.01495-15.

Hayden, R.T., Shahbazian, M.D., Valsamakis, A., Boonyaratanakornkit, J., Cook, L., Pang, X.L., Preiksaitis, J.K., Schönbrunner, E.R., Caliendo, A.M., 2013. Multicenter evaluation of a commercial cytomegalovirus quantitative standard: effects of commutability on interlaboratory concordance. J. Clin. Microbiol. 51, 3811-3817. https:// doi.org/10.1128/JCM.02036-13.

Heemann, U., Abramowicz, D., Spasovski, G., Vanholder, R., 2011. Endorsement of the kidney disease improving global outcomes (KDIGO) guidelines on kidney transplantation: a European renal best practice (ERBP) position statement. Nephrol. Dial. Transplant. 26, 2099-2106. https://doi.org/10.1093/ndt/gfr169.

Kim, K.Y., Le, Q.-T., Yom, S.S., Ng, R.H.W., Chan, K.C.A., Bratman, S.V., Welch, J.J., Divi, R.L., Petryshyn, R.A., Conley, B.A., 2017. Clinical utility of epstein-barr virus DNA testing in the treatment of nasopharyngeal carcinoma patients. Int. J. Radiat. Oncol. Biol. Phys. 98, 996-1001. https://doi.org/10.1016/j.ijrobp.2017.03.018.

Kotton, C.N., Kumar, D., Caliendo, A.M., Asberg, A., Chou, S., Danziger-Isakov, L., Humar, A., 2013. Updated international consensus guidelines on the management of cytomegalovirus in solid-organ transplantation. Transplantation 96, 333-360. https:// doi.org/10.1097/TP.0b013e31829df29d.

Lucic, D., Jones, S., Wiesneth, R., Barry, C., Webb, E., Belova, L., Dolan, P., Ho, S., Abravaya, K., Cloherty, G., 2013. Impact of the new Abbott mPLUS feature on clinical laboratory efficiencies of Abbott RealTime assays for detection of HIV-1, hepatitis C virus, hepatitis B virus, Chlamydia trachomatis, and Neisseria gonorrhoeae. J. Clin. Microbiol. 51, 4050-4054. https://doi.org/10.1128/JCM.01672-13.

Martinez, O.M., Krams, S.M., 2017. The immune response to Epstein Barr virus and implications for posttransplant lymphoproliferative disorder. Transplantation 101, 2009-2016. https://doi.org/10.1097/TP.0000000000001767.

Navarro, D., San-Juan, R., Manuel, O., Giménez, E., Fernández-Ruiz, M., Hirsch, H.H., Grossi, P.A., Aguado, J.M., 2017. Cytomegalovirus infection management in solid organ transplant recipients across European centers in the time of molecular diagnostics: an ESGICH survey. Transpl. Infect. Dis. 1-12. https://doi.org/10.1111/tid. 12773.

Preiksaitis, J.K., Hayden, R.T., Tong, Y., Pang, X.L., Fryer, J.F., Heath, A.B., Cook, L., Petrich, A.K., Yu, B., Caliendo, A.M., 2016. Are we there yet? Impact of the first international standard for cytomegalovirus DNA on the harmonization of results reported on plasma samples. Clin. Infect. Dis. 63, 583-589. https://doi.org/10.1093/ cid/ciw370.

R Core Team, 2016. R: a Language and Environment for Statistical Computing. R Foundation for Statistical Computing, Vienna, Austria n.d., [WWW Document]. URL https://www.r-project.org/. https://www.r-project.org/.

Ruf, S., Wagner, H.-J., 2013. Determining EBV load: current best practice and future requirements. Expert Rev. Clin. Immunol. 9, 139-151. https://doi.org/10.1586/eci. 12.111.

Salmona, M., Fourati, S., Feghoul, L., Scieux, C., Thiriez, A., Simon, F., Resche-Rigon, M., LeGoff, J., 2016. Automated quantification of Epstein-Barr Virus in whole blood of hematopoietic stem cell transplant patients using the Abbott m2000 system. Diagn. Microbiol. Infect. Dis. 85, 428-432. https://doi.org/10.1016/j.diagmicrobio.2016. 04.017. 
Schnepf, N., Scieux, C., Resche-Riggon, M., Feghoul, L., Xhaard, A., Gallien, S., Molina J.M., Socié, G., Viglietti, D., Simon, F., Mazeron, M.C., LeGoff, J., 2013. Fully automated quantification of cytomegalovirus (CMV) in whole blood with the new sensitive Abbott realTime CMV assay in the era of the CMV international standard. J. Clin. Microbiol. 51, 2096-2102. https://doi.org/10.1128/JCM.00067-13.

Semenova, T., Lupo, J., Alain, S., Perrin-Confort, G., Grossi, L., Dimier, J., Epaulard, O., Morand, P., Germi, R., French EBV Study Group, 2016. Multicenter evaluation of whole-blood epstein-barr viral load standardization using the WHO international standard. J. Clin. Microbiol. 54, 1746-1750. https://doi.org/10.1128/JCM. 03336-15.

Tang, L., Sun, Y., Buelow, D., Gu, Z., Caliendo, A.M., Pounds, S., Hayden, R.T., 2016. Quantitative assessment of commutability for clinical viral load testing using a digital PCR-based reference standard. J. Clin. Microbiol. 54, 1616-1623. https://doi.org/10. 1128/JCM.03346-15.

Torre-Cisneros, J., Aguado, J.M., Caston, J.J., Almenar, L., Alonso, A., Cantisán, S., Carratalá, J., Cervera, C., Cordero, E., Fariñas, M.C., Fernández-Ruiz, M., Fortún, J., Frauca, E., Gavaldá, J., Hernández, D., Herrero, I., Len, O., Lopez-Medrano, F., Manito, N., Marcos, M.A., Martín-Dávila, P., Monforte, V., Montejo, M., Moreno, A., Muñoz, P., Navarro, D., Pérez-Romero, P., Rodriguez-Bernot, A., Rumbao, J., San
Juan, R., Vaquero, J.M., Vidal, E., 2016. Management of cytomegalovirus infection in solid organ transplant recipients: SET/GESITRA-SEIMC/REIPI recommendations. Transplant. Rev. 30, 119-143. https://doi.org/10.1016/j.trre.2016.04.001.

Tsai, H.-P., Tsai, Y.-Y., Lin, I.-T., Kuo, P.-H., Chen, T.-Y., Chang, K.-C., Wang, J.-R., 2016. Comparison of two commercial automated nucleic acid extraction and integrated quantitation real-time PCR platforms for the detection of cytomegalovirus in plasma. PLoS One 11, e0160493. https://doi.org/10.1371/journal.pone.0160493.

Vinuesa, V., Solano, C., Giménez, E., Navarro, D., 2017. Comparison of the artus EpsteinBarr virus (EBV) PCR kit and the Abbott RealTime EBV assay for measuring plasma EBV DNA loads in allogeneic stem cell transplant recipients. Diagn. Microbiol. Infect. Dis. https://doi.org/10.1016/j.diagmicrobio.2017.02.010.

Wattles, B., Kim, A., Cheerva, A., Lukas, K., Elder, J., 2017. Cytomegalovirus treatment in pediatric hematopoietic stem cell transplant patients. J. Pediatr. Hematol. Oncol. 39, 241-248. https://doi.org/10.1097/MPH.0000000000000730.

Wolff, D.J., Heaney, D.L., Neuwald, P.D., Stellrecht, K.A., Press, R.D., 2009. Multi-site PCR-based CMV viral load assessment-assays demonstrate linearity and precision, but lack numeric standardization. J. Mol. Diagn. 11, 87-92. https://doi.org/10.2353/ jmoldx.2009.080097. 